Supplementary Information (2 pages)

\title{
Power Densities Using Different Cathode Catalysts (Pt and CoTMPP) and Polymer Binders (Nafion and PTFE) in Single Chamber Microbial Fuel Cells
}

\author{
Shaoan Cheng ${ }^{1}$, Hong $\operatorname{Liu}^{1}$ and Bruce E. Logan ${ }^{1,2} *$ \\ ${ }^{1}$ Department of Civil and Environmental Engineering, \\ ${ }^{2}$ The Penn State Hydrogen Energy $\left(\mathrm{H}_{2} \mathrm{E}\right)$ Center, \\ The Pennsylvania State University, \\ University Park, PA, 16802, U.S.A
}

*Corresponding Author

Phone: 814-863-7908, Fax: 814-863-7304, Email: blogan@psu.edu 


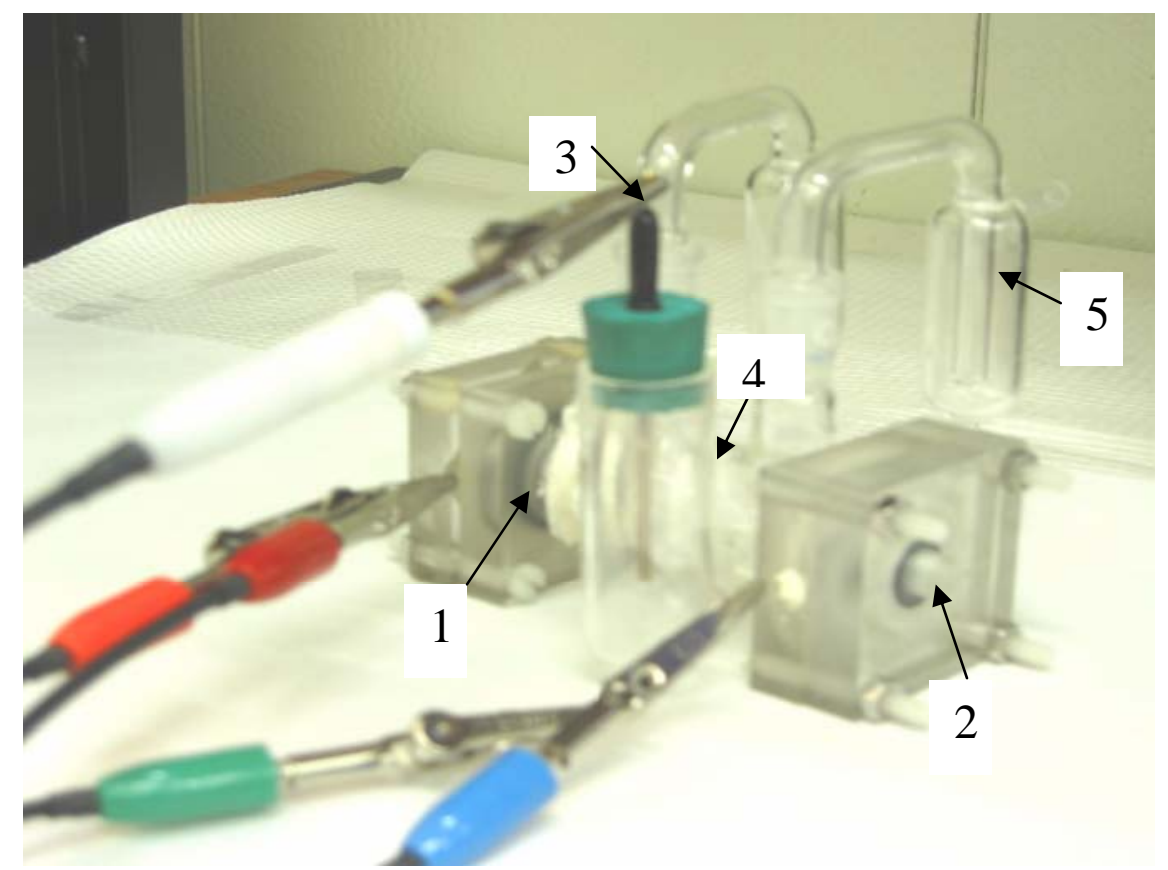

Figure S-1.

Electrochemical cell used to examine cathode performance as a function of Pt loading and chemical binder. 1---Counter electrode: Platinum plate. 2---working electrode: air cathode which The catalyst coated side of cathode was placed facing the solution, with the uncoated side exposed directly to air. 3--- Reference electrode: Ag/AgCl. 4---Sintered glass to separate cell to two chambers. 5---water seal. 